\title{
Range of Dagestan grape varieties and measures to improve it
}

\author{
M.G. Magomedov*, O.M. Ramazanov, G.A. Makuev, A.Z. Dalgatova and A.M. Ramazanov \\ FSBEI HE Dagestan State Agrarian University named after M.M. Dzhambulatov, 367032 Makhach- \\ kala, Russia
}

\begin{abstract}
The article briefly describes the measures taken in the Russian Federation for the development of the viticulture and wine industry. It is proved that Dagestan is an ancient and unique region of viticulture and winemaking. The basics of forming the varietal composition of the region's vineyards are revealed. Its condition is shown, shortcomings and improvement measures in Dagestan are noted. The main requirements for the formation of a grape range varieties in a particular region or district are disclosed. Functions that allow to implement a properly selected grape range of varieties are defined. The work analyzes the presence of varieties included in the State Register of Selection Achievements in the varietal composition of vineyards of the Russian Federation and the Republic of Moldova. The modern varietal composition of Dagestan vineyards is characterized, and its structure for the period 1930-2015 is analyzed. The article provides information about the current composition of Dagestan vineyards by maturation period, as well as by biological, economic and technological indicators of about 130 native and selected grape varieties.
\end{abstract}

\section{Introduction}

In recent years, our country has taken very serious measures to further develop the domestic viticulture and wine industry: wine products are recognized as agricultural products, not alcoholic, and producers of grapes and wine have the right to enjoy all the benefits established by the laws of the Russian Federation in the sphere of agriculture development; the amount of subsidies for the laying, maintenance and installation of the espalier was significantly increased and annually amount to 339 thousand rub. per hectare; duties on the production of wine from domestic grapes were reduced from 800 to 65 thousand rubles; the "Law on grapes and wine" was adopted, and other measures are being taken to substitute import of grape and wine products.

In this regard, in all viticultural regions of the country, activities have been intensified to further develop the viticultural and wine-making industry, including expanding the area of grape plantations and improving their varietal composition. Based on this research, the study of the range of grape varieties and measures to improve it, including in the Republic

${ }^{*}$ Corresponding author: mr.gazi@yandex.ru 
of Dagestan - one of the major regions of viticulture and winemaking is of great scientific and practical interest.

One of the main centers of grape origin and its introduction into culture, according to N.I. Vavilov, the founder of the doctrine of the centers of origin of cultivated plants, is the Caucasus hearth, which includes the territory of modern Georgia, Azerbaijan, Armenia and part of Dagestan[1]. The grape crop was not introduced to Dagestan from other regions, but was born locally, without the influence of neighbors, where grapes were already grown in the V-IV centuries BC [2]. About 150 specific native grape varieties have been identified in the Republic [3], and it is the main region of origin or the largest distribution of grape varieties in Russia [4]. The history of Russian winemaking began in Derbent [5], and in Kizlyar - cognac production in Russia [2]. The above facts indicate that Dagestan is an ancient, unique and original region of viticulture and winemaking, in which the range of grape varieties was formed specifically at various stages of development of the viticultural and winemaking industry of the Republic. This article is devoted to the study of this problem.

\section{Materials and methods}

All registrations, analysis and determinations were carried out according to standard techniques: bio-economic and agro-biological evaluation of varieties - according to M.A. Lazarevsky (1946) [6], technological evaluation of varieties - according to N.N. Prostoserdov (1946) [7], G.S. Morozova (1987) [8] and S.Yu. Dzheneeva (1987) [9].

\section{Results and discussion}

Thanks to the measures taken, the total area of vineyards, the gross harvest of grapes and their industrial processing have grown significantly in the country in recent years. For example, the total area of vineyards in 2018 was 93.5 thousand hectares and increased by $5.0 \%$ compared to 2015 . These indicators in the following three main grape-producing regions of the country, respectively, were: Krasnodar territory 26.6 thousand ha and $5.1 \%$; the Republic of Dagestan - 25.5 thousand ha and 11.4\%; Republic of Crimea - 24.4 thousand ha and $5.1 \%$.

Naturally, in the development of the viticulture and wine industry in our country, it is extremely important to improve the range of varieties of any viticultural region, including the Republic of Dagestan, which is one of the main subjects of the Russian Federation, where viticulture and winemaking have always been priority sectors of the Republic's economy. In the beginning, we will understand what is the range of grape varieties of a particular viticultural region and what are the main principles of its formation, role and functions.

Range of varieties is a group of varieties united by functional, biological, and economically valuable characteristics that most fully corresponds to the ecological conditions of the agroterritory of growth. The range of varieties of grape plantations is being improved by introducing varieties included in the State register of varieties approved for use in production in Russia, obtained by naturalization, introduction, combinative and clone selection. This is a natural process to improve the quality of the complementary set of varieties in a particular region or zone in order to improve economic productivity of varieties and quality of grapes and its products, and the profitability of the entire wine industry of this agroterritory. 
An important condition for improving the range of grape varieties is to increase its adaptability by increasing the share of local varieties that allow to form a competitive range of varieties that meets the principles of modern high-efficiency production.

All the best properties of grape varieties and clones are shown in the environmental conditions of their selection environment. In these conditions, they realize their productive, biological and adaptive potential to the greatest extent, have stable fruiting and good product quality, low costs in the technological process[10-13].

The primary role of range of varieties is: specialization grape producing and processing plant, district, area or region; full involvement of agro-ecological potential in production of grape plants in order to maximize the implementation of the level of economic productivity of grapes and whole ampelocenosis of the enterprise of the district and the overall region; provision of economic and social stability of the subject's production (enterprise, region, republic, territory, region); increase of economic efficiency of viticulture and winemaking and their profitability within the enterprise and in the district and region.

A properly selected range of grape varieties contributes to achieving the following main functions: socio-economic - every 100 ha of plantations allow to provide employment of 40-50 people, to replenish the budgets of all levels; consumer-health - to meet the growing demands of the population in healthy products of high quality, based on the supply of easily digestible consumer product, common, children's, dietary and medical nutrition, rich in natural sugars, organic acids, vitamins, minerals, amino acids, including irreplaceable ones.

Grapes contribute to improving the health of the population, thanks to the ampeloteropic properties of both fresh grapes and about 50 products of its processing, most of which have medicinal properties. Therefore, it is a valuable product in the health food industry.

As already noted, the production uses grape varieties included in the State Register of Selection Achievements. According to the FSBSI North Caucasus Federal Research Center for Horticulture, Viticulture, and Winemaking (FSBSI NSFRCHVW), 174 varieties, including 57 table varieties and 117 technical varieties, have been used in Russian grape plantations in recent years out of 256 varieties included in the State Register. The plantings are dominated by 30 varieties, which occupy $70 \%$ of the country's planting area. The largest share is accounted for varieties of Western European selection. The share of other varieties is $1 \%$ of each genotype[14]. According to the source, the largest areas among table varieties are: Moldova (4725 ha), Augustine (1988 ha), Agadai (1018 ha), Hamburg Muscat (693 ha), Italy (583 ha), and among technical varieties - Rkatsiteli (14459 ha), CabarneSauvignon (5098 ha), Chardonnay (3551 ha), Aligote (2869 ha), Bianca (2626 ha), Riesling Rhenish (2580 ha), Saperavi (2000 ha), Pervenets Magaraga (1904 ha), Merlot (1818 ha), Citron Magaraga (1418 ha), Levokumsky (1406 ha), Pinoblan (1347 ha), Sauvignon (1234 ha), etc.

Today, the State Register includes 16 varieties of Dagestan, including 7 native and 9 breeding varieties, which is $5.9 \%$ of the total number of grape varieties included in the State Register of Selection Achievements approved for use in production in 2019.

Today, in the vineyards of Dagestan, only three varieties Agadai, Narma and Khatmi are represented among these varieties, which in addition to Agadai ocupy scanty areas: Narma 2.0 ha, Khatmi -1 ha or $0.01 \%$ of the total area of grape plantations in the Republic and $0.02 \%$ of the area occupied by table and universal varieties[17].

According to the Ministry of Agriculture of the Republic of Dagestan in 2016, the varietal composition of vineyards of agricultural enterprises of the Republic was represented by 48 grape varieties (22.9 thousand ha), including 26 technical varieties (15.4 thousand ha or $67.2 \%)$ and 22 varieties of table and table-technical (7.5 thousand ha or $32.8 \%$ ).

Among technical varieties, the largest areas (83.4\%) were occupied by 13 varieties: Rkatsiteli - 7918.8 ha (51.5\% of the total area occupied by technical varieties), Riesling - 
935.5 ha (3.7\%), Chardonnay - 572.8 ha (3.7\%), Levokumsky - 490.1 ha $(3.2 \%)$, White Sauvignon - 276.3 ha (1.8\%), Cabernet Sauvignon - 258.3 ha (1.7\%), Uny Blanc - 189.0 ha $(1.2 \%)$, Merlot - 139.5 ha (0.9\%), Podarok Magaracha - 109.3 ha and Saperavi - 109.5 ha $(0.7 \%$ each). The remaining 13 varieties occupied $6.1 \%$, and the variety mix $-13.6 \%$ of the area occupied by technical varieties.

Among table and table-technical varieties, the largest areas $(60.5 \%)$ were occupied by 7 varieties: Augustine -1636.7 ha $(21.8 \%$ of the total area occupied by table varieties), Moldova - 1505.9 ha (20.1\%), Agadai - 706.2 ha (9.4\%), Italy - 215.5 ha $(2.8 \%)$, Premier 159.1 ha $(2.1 \%)$, Zala dend - 97.5 ha and Hamburg Muscat -97.0 ha (1.3\% each). The remaining 13 varieties occupied $1.8 \%$, and the variety mix $-35.3 \%$ of the area occupied by table and table-technical varieties. Augustine and Moldova varieties occupy $45 \%$ of the area occupied by all table grape varieties of the Republic and $13.8 \%$ of the total area of vineyards.

Thus, the above-listed 13 technical and 7 table grape varieties determine the structure of modern grape plantations in the Republic, occupying $83.4 \%$ of technical varieties, respectively, and $60.5 \%$ of the area of table and table-technical varieties.

Rational selection of grape varieties in Dagestan is associated with a wide variety of environmental conditions, due to the combined impact of the sea, steppes, and high mountains. This makes it possible to grow different varieties of grapes even within the same area, both according to the lines of maturation and for the purposes of use. Therefore, probably, the vineyards of the Republic have always been marked by multi-variety. So according to various sources, in 1960-1965 - 90, in 1970 - 60, 2015 - 38 varieties were leveled. Or in $1955-1960$, the zoned range of grape varieties consisted of 48 varieties, including 22 (45.8\%) native varieties, in 1967 it consisted of 60 and 17 (38.6\%), respectively. Analysis of changes in the varietal state of vineyards in Dagestan over the past 100 years has shown that it has changed significantly at various stages of development of the viticultural and wine-making industry of the Republic[15,16]. During this time (since 1930), the range of varieties has been updated by more than $90 \%$. From it indigenous varieties of Asylkar, Gulyabi dagestansky, Budayshuli, Gimra, Dubut, Koz yzyum, Makhbortsibil, Sarakh, Tygiz, Hindogny, Yay izyum belyi and introduced - Semillon and Husayne were bred. They were replaced by introduced ones, although many of them turned out to be ineffective due to their low level of realization of the potential of economic productivity in the agroecological conditions of the Republic. Today, there are very few local native and selective varieties in the Republic's range of grape varieties. Grape varieties selected by the branch of the FSBSI NSFRCHVW SSI "Derbent Selection Experimental Station of Viticulture and Vegetable Growing" (DSESVaVG), recommended for wide production cultivation of canteens: Vezne, Ag izyum urozhaynyi, Gulyabi urozhaynyi, Dagestanskiy, Zhemchuzhina Derbenta, Maral, Muscat Derbentskiy, Muscat Peitel, Muscat yuzhnodagestanskiy, NarynKala, Primetny, Salam, Samur, Kishmish Derbentskiy, Khatmi urozhaynyi; technical: Gimranovyi, Stoykiy, Slava Derbenta, etc. do not yet occupy a proper place in the vineyards of the Republic[17]. The above also refers to the native varieties Ag izyum, Alyi terskiy, Asyl Kara, Gimra, Gyulyabi Dagestanskiy, Narma, Khatmi, Makhbortsibil, etc. The dynamics of changes in the share of native grape varieties in the total assortment of vineyards in Dagestan for the period from 1930 to 2015 is shown in figure 1, which shows that the share of native varieties decreased by almost 30 times. Despite the fact that among the total number of native varieties of the Russian Federation, as already noted, the share of Dagestani varieties is about 150 or $57.7 \%[15]$. Dagestan is the ancient and main region of origin or the largest distribution of grape varieties in Russia [4]. 


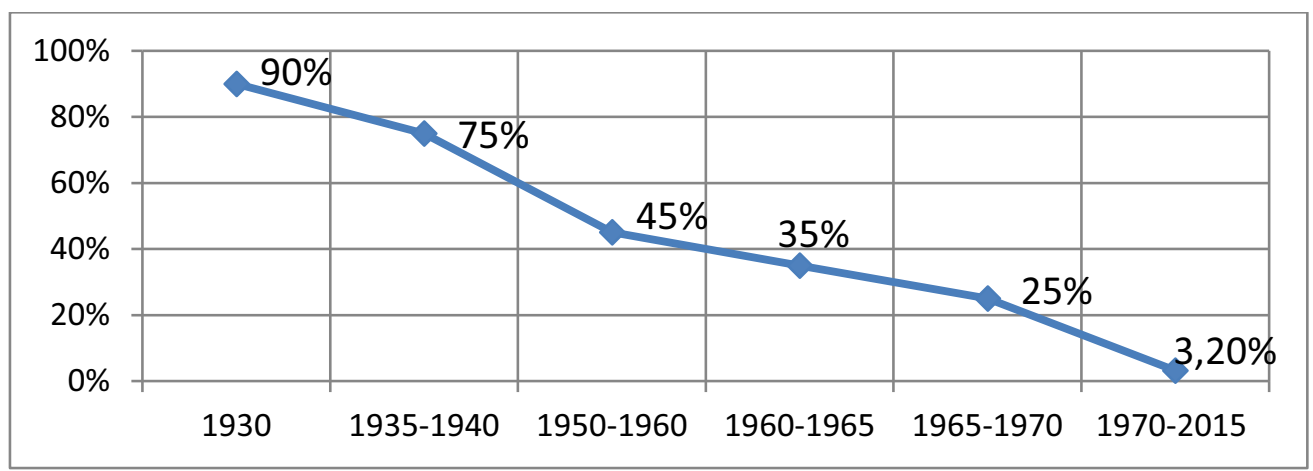

Fig. 1. Dynamics of changes in the share of native grape varieties in total range of varieties of vineyards in Dagestan for 1930-2015, \% (according to M.G. Magomedov, 2018).

However, researches of the FSBSI NSFRCHVW established that the level of realization of the economic productivity potential of grape varieties of different origin varies from 66 (Anapa) to 52\% (Western Europe) and domestic and autochthonous grape varieties, in contrast to the introduced they possess hereditary traits of high adaptability, productivity and quality, and accordingly they exhibit their best economic-valuable traits when growing in their places of origin[14]. Hence, the local grape varieties of Dagestan are a serious reserve for improving the varietal composition of the region's vineyards.

The album "Best grapes of the USSR", released as a color bupplement to the tenvolume publication "Ampelography of the USSR", contains color drawings and photographs of 180 grape varieties - the most common and zoned in various regions of the former USSR, including 10 native varieties of Dagestan: Agadai, Ag izyum, Alyi terskiy, Asyl Kara, Gimra, Gyulyabi dagestanskiy, Narma, Rish baba, Khatmi, Yay izyum rozovyi. According to the All-Union census of grape plantations in 1940, some of these varieties in the Dagestan vineyards occupied significant areas: Agadai - 605 ha; Alyi terskiy (only in the Kizlyar district) - 347 ha; Asyl Kara - 659 ha; Gyulyabi dagestanskiy - 190 ha; Narma - 824 ha. Unfortunately, these best native varieties of Dagestan, which gave glory to Dagestani wines and cognacs, are practically absent in the range og grape varieties of the Republic today or occupy scanty areas, except for the Agadai variety. As already noted, in the last few decades, the share of native grape varieties in the vineyards of the Republic does not exceed $3.2 \%$.

Table 2 shows data that characterize the current varietal composition of Dagestan vineyards by maturation period[19]. As can be seen from the above data, early-mid-season and late varieties predominate in the vineyards of the Republic among table and table-technical varieties, and among technical varieties - varieties of mid-season and late maturation periods.

In the vineyards of the Republic, there are very few varieties of extreme early, very early and early maturation. So, a group of varieties with a late maturation period is represented by 1 variety, very early and early -5 and 4 varieties, respectively. The total area occupied by these varieties among table and table-technical - 1027 ha $(6.67 \%)$. There are no very late-maturing grape varieties in the range of grape varieties, although there are more than enough of these varieties among the native varieties of the Republic.

There are also no varieties with complex resistance and seedless varieties. As already mentioned, the range of varieties of the Republic there are practically no varieties of selection of the Derbent DSESVaVG. The above implies the need to improve the assortment of vineyards in the Republic. 
Table 2. The distribution of the varietal composition of the vineyards of Dagestan by maturation period (according to M.G. Magomedov, 2018)

\begin{tabular}{|c|c|c|c|c|c|c|}
\hline \multirow{2}{*}{$\begin{array}{l}\text { Group of varie- } \\
\text { ties by mat- } \\
\text { uration pe- } \\
\text { riod }\end{array}$} & \multicolumn{3}{|c|}{ Table and table-technical } & \multicolumn{3}{|c|}{ Technical } \\
\hline & $\begin{array}{c}\text { Number } \\
\text { of } \\
\text { va- } \\
\text { rie- } \\
\text { ties } \\
\end{array}$ & ha & $\begin{array}{c}\% \text { of the area } \\
\text { of table } \\
\text { and tech- } \\
\text { nical vari- } \\
\text { eties }\end{array}$ & $\begin{array}{c}\text { Number } \\
\text { of } \\
\text { va- } \\
\text { rie- } \\
\text { ties } \\
\end{array}$ & ha & $\begin{array}{c}\% \text { of the area } \\
\text { of tech- } \\
\text { nical va- } \\
\text { rieties }\end{array}$ \\
\hline Extreme early & 1 & 1.3 & 0.02 & - & - & - \\
\hline Very early & 5 & 93.0 & 1.24 & 2 & 161.5 & 1.05 \\
\hline Early & 4 & 287.0 & 3.84 & 3 & 865.5 & 5.62 \\
\hline $\begin{array}{c}\text { Early-mid- } \\
\text { season }\end{array}$ & 1 & 1636.7 & 21.90 & 2 & 125.3 & 0.81 \\
\hline Mid-season & 2 & 3.0 & 0.04 & 8 & 3064.6 & 19.92 \\
\hline Mid-late & 3 & 118.1 & 1.58 & 8 & 971.4 & 6.31 \\
\hline Late & 6 & 2505.1 & 33.52 & 3 & 8106.3 & 52.68 \\
\hline Very late & - & - & - & - & - & - \\
\hline $\begin{array}{c}\text { Varietal mix: } \\
\text { agricultural } \\
\text { enterprises } \\
\text { and PF PSP }\end{array}$ & - & $\begin{array}{c}138.6 \\
2691.6\end{array}$ & $\begin{array}{c}1.85 \\
36.01\end{array}$ & - & $\begin{array}{c}205.7 \\
1888.1\end{array}$ & $\begin{array}{c}1.34 \\
12.27\end{array}$ \\
\hline Total & 22 & 7474.4 & 100 & 26 & 15388.4 & 100 \\
\hline
\end{tabular}

To do this, it is very important to know what the grape assortment of Dagestan is in terms of its biological, economic and technological indicators. Long-term research on the study of biological, economic and technological characteristics and properties of 106 native and 23 breeding grape varieties of Dagestan according to the international ИРОV methodology and generally accepted methods $[6,7,8,9]$, it was found that more than $56 \%$ of Dagestani varieties are varieties of late and mid-season maturity [19]. Among them, there are no varieties with a late maturation period. There are significantly few varieties of very early $(4.6 \%)$ and early $(3.0 \%)$ maturation periods.

According to the source, more than $55 \%$ of Dagestan varieties are table varieties, $16.8 \%$ are table-technical, and $27.5 \%$ are technical. According to the size of bunches and berries, native and selective grape varieties of Dagestan are distributed as follows: the average size of bunches and berries are 43.5 and $41.2 \%$, respectively; medium and large - 20.6 and $13.0 \%$; large -29.8 and $34.3 \%$.

Among native varieties, varieties with average bunch sizes predominate $-45.4 \%$, and among breeding varieties - large bunches $-47.8 \%$. Similarly, there are native and breeding varieties also by berry size.

About $76 \%$ of Dagestan grape varieties are characterized by low (29.2\%), low to medium (17.0\%) and medium (29.8\%) mass concentration of sugars in berry juice. Only $24 \%$ of varieties have high and very high sugar content.

About $72 \%$ of native and selected grape varieties of the Republic have an average (44.5\%), medium to high (12.1\%) and high (15.3\%) mass concentration of titrated acids of berry juice, and $28 \%$ of varieties - low and very low.

Many years of research on the study of mechanical properties established (M.G. Magomedov)[19] that among the 47 grape varieties studied, including 33 native and 14 breeding varieties, $17(36.2 \%)$ varieties have very strong crushing strength, $18(38.3 \%)$ varieties are strong, $9(19.1 \%)$ varieties are medium-strong, and $3(6.4 \%)$ varieties are fragile. Among native varieties, these indicators are respectively $5(15,2 \%), 16(43,5 \%), 9(27,2 \%)$ and $3(9.1 \%)$, and among the breeding varieties there are no varieties whose berries are 
medium-strength or fragile in terms of crushing strength. Among the studied grape varieties, $31(66.0 \%)$ varieties are very strong, $11(23.4 \%)$ are strong, and $5(10.6 \%)$ are medium in strength of attachment to the fruit stalk. Among the studied varieties, there is not a single variety whose berries are weak in terms of strength of attachment to the stalk. Among native varieties, $17(51.5 \%)$ varieties are very strong in terms of strength of attachment to the stalk, $11(33.3 \%)$ varieties are strong, and $5(15.2 \%)$ varieties are medium-strong. In all breeding varieties, the strength of attachment to the stalk of the berries is very strong. Among the native varieties, only theAgadai variety belongs to the highly transportable varieties, and among the breeding varieties - Gulbaar, Dagestanskiy and Muscat derbentskiy. The Tavlinskiy late variety has average transportability among native varieties, and among breeding varieties - Venze, Maral, Muscat transportabelnyi, Muscat yuzhnodagestanskiy, Naryn-kala, Salam and Samur.

It should be noted that the heads of PF and PSP when selecting grape varieties pay special attention to the principles of ensuring the varietal conveyor of table grapes, i.e. the range of varieties includes varieties of various maturation periods, from extreme early and early - Arcadia, Kodryanka, Cardinal, Vostorg, Super ran Bolgar, Augustine to late and very late - Agadai, Moldova, Italy, Taifi rozovyi, Muscat derbentskiy, etc., whose products can be transported over long distances and provide the population with fresh grapes from the bush for 3.5-4.0 months per year. Having laid the grapes of late varieties for storage it can be possible to extend the period of consumption of fresh grapes from conventional storage until the new year, and with the correct selection of varieties and strict implementation of agrotechnical methods of cultivation for long-term storage and storage technology in a controlled atmosphere (CA) - until March-April [18-21].

It should be noted that many owners of PF and PSP grow grapes for sale on the market. Here, the selection of varieties must be carried out taking into account the interests of the consumer, the commodity and taste qualities of grapes. Today, the Russian consumer prefers products of market or commercial grape varieties that have large or medium bunches, large beautiful berries (elongated or oval) of various colors, crisp and juicy flesh.

It should be noted that the range of table grape varieties of Dagestan is very poorly represented by high-quality varieties, although in the grape market, consumers are in great demand for such local varieties as Kishmish derbentskiy, Vezne, Dokur, Gulyabi dagestanskiy, Muscat derbentskiy, introduced - Kishmish luchistyi, Kishmish vengesakiy, Moldova, Taifi rozovyi and others. Therefore, it is necessary to expand the area for these varieties and fill the market of seedless grape varieties. At the same time, special attention should be paid to local early and very early varieties: Salam, Yay izyum belyi, Yay izyum rozovyi, Yay izyum chernyi, Yantar dagestanskiy, etc.

Given that Dagestan is the most Southern and most heat-efficient viticultural and winegrowing region of the Russian Federation with a wide variety of agroecological conditions, there are excellent opportunities for growing seedless grapes and producing dried products using tent shelters and solar drying installations, which is confirmed by our long-term research [22,23].

Based on the above, we can conclude that the main disadvantages of the existing range of grape varieties in Dagestan are the following:

- The multiplicity and low level of realization of economic productivity potential of cultivated varieties, as a result of increased susceptibility, especially of introduced varieties, to biotic and abiotic stress manifestations, which complicates the agricultural technology of growing grapes due to increased chemical pressure on the ampelocenosis of the region with deterioration of the ecological environment and the quality of grapes and their processed products. 
- A critically small proportion of native (autochthonous) varieties (3.2\%) and almost no local breeding of varieties with an increased adaptive potential to the manifestation of biotic and abiotic stress situations when they are grown in the origin agroterritory.

- A small proportion of table varieties of extreme early $(0.02 \%)$, very early $(1.24 \%)$, early $(3.84 \%)$, medium $(0.04 \%)$ and the absence of very late maturation periods, and as a result, the lack of balanced varietal and environmental conveyors that allow delivering fresh grapes from the bush to the market within 3.5-4.5 months based on the rational selection of varieties of different maturation periods and growing them in optimal agroecological and agrotechnological conditions of individual micro zones and regions of the Republic, which are so rich in Dagestan.

- The lack of seedless varieties for fresh consumption and use for drying and confectionery purposes, the lack of highly adaptive varieties with high taste and commoditytechnological advantages.

- The absence of technical varieties of extreme early and very late and a small proportion of very early $(1.05 \%)$, medium $(0.81 \%)$ maturation periods and varietal and environmental conveyors of grape supplies for processing for at least 3.0-3.5 months. Deficite of red technical varieties of the early maturation period for the production of light wines.

In connection with the transition in the Republic to the production of wines with protected designation of origin and the need to address the problems within eco-bio-agrotechnological system "Climate-soil-grape-agricultural cultivation-value of the yield and chemical-technical features-technology of refining-quality of finished products" requires the identification of micro-districts, areas and varieties of cultivated grapes, list of agronomic practices, maximum yield, technology of grape processing and other measures. All this will require careful selection of varieties for each micro zone in order to produce the highest quality wines of any type

It should also be noted that both in improving the assortment and the technology of growing and processing it for wine in Dagestan, an important role was played by the model nursery garden and estate of the Governor of the Caucasus I.I. Vorontsov-Dashkov in 1890 in the area of "Gedzhukh" created in Derbent in 1848. . Here local gardeners first got acquainted with European varieties and advanced at that time techniques of grape cultivation and winemaking technologies. The best European varieties were grown in the estate: Cabernet Sauvignon, White Muscat, Saperavi, Pinot Gris, Semillon, Riesling, etc. This time can be considered as the first period of appearance of foreign selection varieties in the vineyards of Dagestan.

At the same time, it cannot be excluded that introduced grape varieties were not brought here earlier due to the construction of the Kizlyar fortress on the Terek river in 1736 and the settlement of natives of some Caucasian tribes - Armenians, Georgians, Persians, Kabardins, etc.

A special role in the formation of the range of grape varieties was played by the scientists of DSESVaVG, who identified and compiled ampelographic characteristics of almost all Dagestani native and more than 30 bred grape varieties[24].

\section{Conclusions}

Today there is urgent need for a radical improvement of the assortment of vineyards of Dagestan, and to do this in the first place to eliminate the shortcomings mentioned in the article, using the maximum potential of the well-known local native and selection varieties: Alyi terskiy, Asyl kara, Gyulyabi dagestanskiy, Narma, Khatmi, etc., Bulatovskiy, Muscat derbentskiy, Muscat transportabelniy, Venze, Dolchatyi, Kishmish derbentskiy, Slava Der- 
benta and Gimra novyi, especially high yielding clones of Ag izyum urozhaynyi, Gulyabi urozhaynyi, Khatmi urozhaynyi, etc., as well as the best varieties of domestic breeding possessing complex resistance to several biotic and abiotic factor of the growth environment: Bianca, Vostorg, Victoria, Viorica, Talisman, Original, Pervenets Magaracha, Levokumskiy, Tsitronnyi Magaracha, etc. For this purpose in the Republic it is necessary to produce their own planting material that meets the requirements of the current normativetechnical documentation.

At the same time, special attention should be paid to the production of grafted planting material, which is not produced in Dagestan today, growing 3.0-3.5 million grafted seedlings per year.

\section{References}

1. K.V. Smirnov, T.I. Kalmykova, G.S. Morozova, Viticulture (Moscow: Agropromizdat, 1987)

2. L.A. Oganesyants, History of viticulture and winemaking in Russia (M.: SSI AllRussian Research Institute of Brewery, Non-alcoholic and Wine Industry of the Russian Academy of Agricultural Sciences, 2009)

3. A.M. Negrul, Ya.F. Katz, History of ampelographic research, Ampelography of the USSR (Moscow: Pishchepromizdat, 1946)

4. M.G. Magomedov, A.N. Alieva, A.K. Rajabov, Problems of regional agribusiness development, 4(20), 34-38 (2014)

5. M. Ballas, Historical and statistical essay of wine-making in Russia (SPb, 1887)

6. M.A.Lazarevsky, Methods of botanical description and agrobiological study of grape varieties, Ampelography of the USSR (Moscow: Pishchepromizdat, 1946)

7. N.N. Prostoserdov Technological characteristics of grapes and products of its processing, Ampelography of the USSR, (Moscow: Pishchepromizdat, 1946)

8. G.S. Morozova, Viticulture with the basics of ampelography (M.: VO "Agropromizdat", 1987)

9. S.Yu. Jeneev, Transportability of grapes, Encyclopedia of viticulture (Kishinev: Ch. ed. of Mold. Sov. Encyclopedia, 1987)

10. V.S. Petrov, T.A. Nudga, E.T. Ilnitskaya, etc. Highly adaptive assortment-basis of sustainable grape production, Developments that shape the modern look of viticulture. (Krasnodar: SSI North Caucasian Federal Scientific Center of Gardening, Viniculture and Wine Growing, 2011)

11. A. Carboneau, Evaluation of grapevine cultivars: ecophysiological adaption and wine quality, VI Intern. Symp. on Grape Breeding (Yalta, Ukraine, 1994)

12. S.V. Levchenko, V.V. Likhovskoi, I.A. Vasylyk [et al.], Phenolic compouds in the Crimean autochthomous grape varieties (2017)

13. S.V.Levchenko, V.A.Volynkin, V.V.Likhovskoi [et al.], Crimean autochthomous grape varieties and effect of using them in breeding (ABSTRACTS International Symposium on Horticulture: Priorities \& Emerging Trends, 2017)

14. V.S. Petrov, Varietal policy in modern viticulture of the Russian Federation, Materials of the regional scientific and practical seminar "Promising varieties and technologies for improving the efficiency of viticulture in the Republic of Dagestan" (2019 
15. M.Ya. Peytel, Zoned grape assortment in the Dagestan (Makhachkala, Dagestan book publishing house, 1959)

16. M.A. Lazarevsky, A.M. Aliev, Grape varieties in the North Caucasus, Rostov-on-don, (1965)

17. M.G. Magomedov, O.M. Ramazanov, Winemaking and viticulture, 3, 4-8 (2017)

18. S.D. Radzhabov, Wine and viticulture, 4, 40-42, 5, 30-32 (2005)

19. M.G. Magomedov Viticulture and winemaking, grapes and wine of Dagestan (Makhachkala: SAU RD "Dagestan book publishing house", 2018)

20. M.G. Magomedov, Grapes: the fundamentals of storage technology, (SPb.: Publishing house "Lan", 2015)

21. M.G. Magomedov, M.D. Mukailov, O.M. Ramazanov, Problems of regional agribusiness development, 4(20), 40-45 (2014)

22. M.G. Magomedov, A.M. Amadziev, Sh.K. Omarov Prospects for drying grapes in Dagestan with the use of gel dryers, Public and personal in the agricultural sector of the Republic of Dagestan (Makhachkala, 1998)

23. Sh.K. Omarov, M.G. Magomedov, Grape varieties for drying in Dagestan, Collection of scientific works of the interreg. scientific practic.conf., ded. to 70th anniversary of the faculty of agricultural technology and commodity science (DSAA, 2002)

24. Ampelography of the USSR (M.: Pishchepromizdat, 1948-1984) 